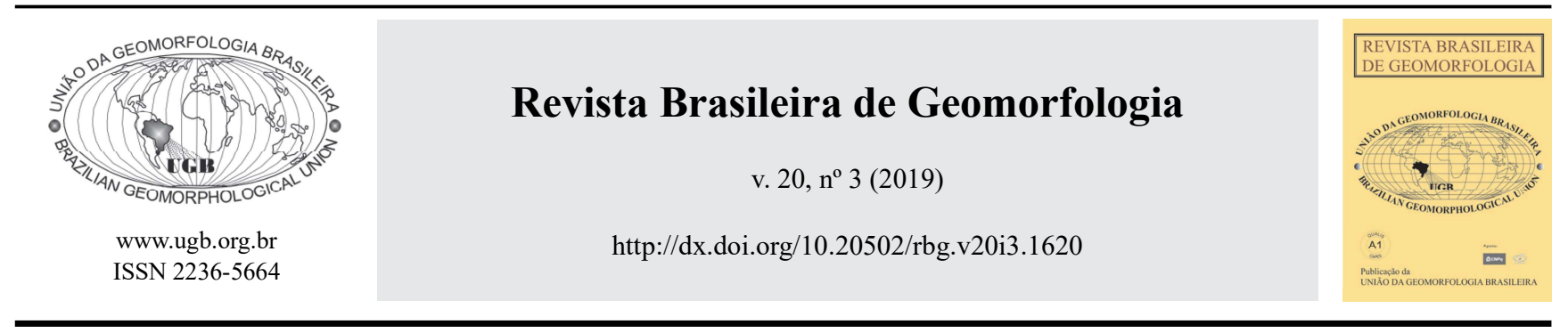

\title{
DATAÇÃO POR LUMINESCÊNCIA OPTICAMENTE ESTIMULADA (LOE) NAS CRISTAS DE PRAIA DO DELTA DO RIO PARAÍBA DO SUL (RJ): CONSIDERAÇÕES SOBRE A EVOLUÇÃO GEOMORFOLÓGICA ENTRE O PLEISTOCENO SUPERIOR E O HOLOCENO
}

\section{OPTICALLY STIMULATED LUMINESCENCE (OSL) DATING OF THE BEACH RIDGES IN THE PARAÍBA DO SUL RIVER DELTA (RJ): CONSIDERATIONS ABOUT THE GEOMORPHOLOGICAL EVOLUTION BETWEEN UPPER PLEISTOCENE AND HOLOCENE}

\author{
Thaís Baptista da Rocha \\ Departamento de Geografia, Universidade Federal Fluminense \\ Av. General Milton Tavares de Souza, s/n ${ }^{o}$, Niterói, Rio de Janeiro. CEP: 24210-346. Brasil \\ ORCID: 0000-0002-5268-8009 \\ E-mail: thaisbaptista@id.uff.br \\ Sérgio Cadena de Vasconcelos \\ Departamento de Geografia e Meio Ambiente, Pontifícia Universidade Católica do Rio de Janeiro \\ Rua Marquês de São Vicente, 225, Rio de Janeiro, Rio de Janeiro. CEP: 22453-900. Brasil \\ ORCID: 0000-0003-3903-1130 \\ E-mail: sergio-cadena@puc-rio.br \\ Thiago Gonçalves Pereira \\ Departamento de Geografia Física, Universidade do Estado do Rio de Janeiro \\ Rua São Francisco Xavier, 524, Rio de Janeiro, Rio de Janeiro. CEP: 20550-01. Brasil \\ ORCID: 0000-0001-6005-3823 \\ E-mail: thiagopereira.uerj@gmail.com
}

Guilherme Borges Fernandez.

Departamento de Geografia, Universidade Federal Fluminense Av. General Milton Tavares de Souza, $s / n^{\circ}$, Niterói, Rio de Janeiro. CEP: 24210-346. Brasil ORCID: 0000-0003-4217-9021

E-mail: guilhermefernandez@id.uff.br

Informações sobre o Artigo

Recebido (Received):

10/03/2019

Aceito (Accepted):

$25 / 05 / 2019$

Palavras-chave:

Barreiras Arenosas Costeiras;

Delta Dominado por Ondas;

\section{Resumo:}

As cristas de praia são feições arenosas construídas pela ação das ondas que marcam posições pretéritas da linha de costa, em função de flutuações no nível do mar e condições de aporte sedimentar, sendo comumente encontradas nas áreas de influência de deltas dominados por ondas. Recentemente elas têm sido datadas pelo método da Luminescência Opticamente Estimulada (LOE), o que tem permitido a reconstrução paleogeográfica de planícies costeiras durante o Quaternário. Além disso, essas cristas também podem ser utilizadas como paleoindicadores de variações do nível do mar. No delta do rio Paraíba do Sul 
Indicadores do Nível do Mar; Progradação; Datação por LOE

\section{Keywords:}

Coastal Sandy Barriers; WaveDominated Deltas; Indicator Sea-Level; Progradation; OSL Dating.
(RJ), os principais modelos de evolução geomorfológica foram construídos a partir de idades obtidas por radiocarbono, cujas cristas de praia nem sempre fornecem materiais para a datação. Nesse sentido, o objetivo do presente trabalho é investigar a geocronologia das cristas de praia do delta do rio Paraíba do Sul, a partir do método da LOE. Foram coletadas 11 amostras no flanco norte do delta, e 10 amostras no flanco sul. Todas as amostras foram analisadas a partir do Protocolo SAR, com 15 alíquotas cada. Os resultados corroboraram muitas discussões anteriormente debatidas, a partir de idades estabelecidas por radiocarbano. Porém, os novos resultados de idades LOE estabelecidos diretamente a partir das cristas

de praia levantaram novas questões acerca da evolução do delta. No flanco norte, a idade N3 (4.130 \pm 580 anos) marca o início da progradação da planície, como resposta ao aporte sedimentar do rio Paraíba do Sul e a diminuição do nível relativo do mar após o Máximo Transgressivo do Holoceno. Os dados geomorfológicos e topográficos mostram que essa progradação foi gerada a partir de regressão forçada. As idades N1 (38.650 3.170 anos) e N2 ( $9.400 \pm 1.300$ anos) mostram que o Pleistoceno Superior e a transição entre o Pleistoceno/Holoceno precisam ser melhor investigados. No flanco sul, a datação nas cristas próximas aos truncamentos erosivos sugere que os ciclos erosivos ou de interrupção da progradação podem ultrapassar um século. As estimativas das taxas de progradação mostram que as taxas foram mais rápidas no flanco sul do que o flanco norte, apresentando cerca de 5,0 m/ano e $3,0 \mathrm{~m} /$ ano, respectivamente. Esse resultado sugere a possibilidade de uma segunda fonte sedimentar, além do rio Paraíba do Sul, responsável pela construção da planície no flanco sul.

\begin{abstract}
:
The beach ridges are sandy landforms built by the waves action that mark paleoshorelines, due to fluctuations in sea level and sediment supply conditions, commonly found in wave-dominated deltas. Recently, they have been dated by the Optically Stimulated Luminescence (OSL) that has allowed the paleogeographic reconstruction of coastal plains during the Quaternary. Furthermore, they can also be used as sea-level indicator. In the Paraíba do Sul river delta (RJ), the main geomorphological evolution models were constructed from ages obtained by Radiocarbon, whose beach ridges don't always provide materials for dating. Therefore, the objective of this study is to investigate the geochronology of the beach ridges of the Paraíba do Sul river delta, through the OSL dating. A total of 21 samples were collected and were analyzed by SAR-protocol, with 15 aliquots each. The results corroborated many discussions previously debated from Radiocarbano dating. However, the new results of OSL dating created new questions about the delta evolution. On the north flank, the age N3 (4.130 \pm 580 years) marks the beginning sandy beach progradation of the delta plain, due to the sand supply and the sea level fall, after the mid-Holocene sea-level maximum. The geomorphological and topographic data show that this progradation was generated from forced regression. The ages N1 (38.650 \pm 3.170 years) and N2 (9.400 \pm 1.300 years) show that Upper Pleistocene and the transition between the Pleistocene / Holocene need to be better investigated. On the south flank, the dating in beach ridges near to erosive truncations suggests that the cycles of erosion or interruption of progradation can exceed a century. Estimates of the progradation rates show that rates were faster on the southern flank than the northern flank, about 5,0 m/year and 3,0 m/year, respectively. This result suggests that there is a second sedimentary source, besides the Paraíba do Sul river, responsible for the construction of the plain on the south flank.
\end{abstract}

\section{Introdução}

As cristas de praia, também conhecidas como cordões arenosos, são feições alongadas construídas pela ação das ondas, comumente encontradas nas planícies costeiras quaternárias, associadas às costas dominadas por ondas (HESP et al. 2005, TAMURA, 2012). Embora a sua gênese normalmente esteja associada aos processos de espraiamento pela ação das ondas que são responsáveis por construir as bermas, a definição de crista de praia pressupõe a característica de ser uma feição reliquiar que, após o processo de progradação do prisma praial, deixa de ser atingida e retrabalhada pela ação diária das ondas (OTVOS, 2000). É nesse sentido, que as cristas de praia também são conhecidas como 
"paleolinhas de praia" e consequentemente são registros geomorfológicos que ajudam a contar a história evolutiva das planícies costeiras (NIELSEN et al. 2006; TAMURA, 2012).

De acordo com Scheffers et al. (2012), as cristas de praia podem ser consideradas como "geo-arquivos" para as investigações acerca das alterações climáticas, variações do nível do mar e até eventos de alta magnitude, como efeitos de tempestade e tsunamis. O potencial de preservação das cristas de praia ocorre normalmente em locais com características de diminuição do nível relativo do mar, soerguimento neotectônico ou emersão glácio-isostática. Especificamente no Brasil, as cristas de praia possuem a sua construção e preservação associadas a um contexto de diminuição do nível relativo do mar nos últimos 5.500 anos AP (ANGULO et al. 2006; MARTIN et al. 2003) e a alta descarga sedimentar de bacias de drenagem que podem formar deltas como o rio Paraíba do Sul, o rio São Francisco e o rio Doce. Nesses casos, as planícies de cristas de praia podem ultrapassar 20 km de extensão. (SCHEFFERS et al. 2012).

Um dos principais métodos de investigação da evolução quaternária dessas planícies costeiras é a geocronologia que, até a década de 90 do século XX, era principalmente realizada através das análises de Radiocarbono. Nesse caso, os principais materiais utilizados para a datação eram a matéria orgânica concentrada nas depressões entre as cristas, troncos de árvores e restos de conchas, conforme mostraram Martin e Suguio (1976), Suguio et al. (1985); Martin et al. (1993). Muitas dessas idades contribuíram não só para a compreensão da evolução das planícies costeiras, como para a construção das curvas de variações do nível relativo do mar nos últimos 7.000 anos para costa brasileira ainda que, posteriormente, Angulo et al. (2006) questionassem sobre a possibilidade de remobilização e transporte de materiais como fragmentos de conchas e madeira, o que poderia resultar em interpretações equivocadas.

Com o posterior aperfeiçoamento das técnicas de datação por Luminescência Opticamente Estimulada (LOE), esta passou a ser uma das técnicas mais utilizadas para a obtenção da geocronologia das cristas de praia (TAMURA, 2012). A medição da luminescência é realizada no grão de quartzo ou feldspato, o que permite determinar quando o mineral foi exposto a luz solar pela última vez e, em outras palavras, determina quanto tempo o mineral permaneceu soterrado, estabelecendo uma idade numérica para um depósito sedimentar (SALLUM et al. 2007). Nesse sentido, como não há a necessidade de analisar materiais secundários ao depósito (matéria orgânica, conchas, madeira) e o material de análise passa a ser o próprio mineral constituinte da feição deposicional, a idade obtida pode ser diretamente associada à sua gênese (TAMURA, 2012).

Segundo Richardson (2001), certos ambientes deposicionais costeiros como dunas e cristas de praias são consideradas boas fontes para datações pelo método da luminescência. No caso das cristas de praia, podemos destacar Murray-Wallace et.al (2002), Banerjee et al. (2003), Argyilan et al. (2005), Bristow e Pucillo (2006), Nielsen et al. (2006), Reiman et al. (2010), Rink e López (2010), Forsyth et al. (2012), Tamura et al. (2017), Botha et al. (2018). De acordo com Nielsen et al. (2006), a investigação geocronológica destas feições permite a construção de modelos evolutivos de planícies, bem como formulação de taxas de progradação da linha de costa, considerando o princípio da continuidade lateral, onde cada crista tem a mesma idade ao longo de seu comprimento. Segundo, se a altimetria de cada crista é conhecida, podem ser formuladas curvas de comportamento do nível relativo do mar.

No Brasil, o potencial das cristas de praia para a geocronologia por LOE ainda está em desenvolvimento. Guedes et al. (2011) investigaram as cristas de praia da Ilha Comprida e estimaram taxas de progradação transversal de 0,13 a $4,6 \mathrm{~m} /$ ano; e taxas de progradação lateral de 5,2 a $30 \mathrm{~m} /$ ano. Bittencourt et al. (2017) encontraram idades entre 2,6 $\pm 0,2$ a 6,3 $\pm 0,4 \mathrm{ka}$, em cordões arenosos na margem da lagoa dos Quadros (RS). Na planície da praia do Cassino, Dillenburg et al. (2017) identificaram fases de progradação nas cristas de dunas frontais (Foredune ridges) e campos de dunas transgressivas, iniciadas a partir dos últimos 5.000 anos. Recentemente, Nascimento et al. (2018) utilizou o método da LOE na planície costeira de São Francisco de Itabapoana (ES) e os resultados 
corroboraram a origem holocênica dos cordões arenosos (cristas de praia), com idades variando entre $5.261 \pm 396$ a $1.940 \pm 158$ anos.

No Rio de Janeiro, as cristas de praia são bem desenvolvidas no Complexo Deltaico do rio Paraíba do Sul (CDRPS). Este está associado às diferentes fases de deposição do respectivo rio ao longo do Quaternário e engloba aproximadamente $1 / 4$ do litoral fluminense. No setor ao sul do CDRPS (figura 1A), Rocha et al. (2013) investigaram a morfoestratigrafia e a geocronologia por LOE das cristas de praias, cujas idades foram próximas a 80.000 anos. Essas cristas de praia formam um dos raros terraços marinhos deposicionais preservados de idade pleistocênica, referente ao Estágio Isotópico Marinho 5a (MIS 5a).

O setor norte do CDRPS, ao norte do Cabo de São Tomé (figura 1A), engloba o delta atual do rio Paraíba do Sul cuja foz marca o limite entre os municípios de São Francisco de Itabapoana e São João da Barra. A geocronologia desse delta foi investigada por Martin et al. (1993), cujas idades foram estabelecidas pelo método do radiocarbono. Nesse caso, a maioria das amostras foram obtidas em ambientes de deposição lagunar, principalmente a partir de fragmentos de conchas. De um total de cerca de 60 amostras, somente sete amostras foram coletadas nas feições de cristas de praia e todas concentradas no flanco norte do delta do rio Paraíba do Sul, cujas idades variaram entre $4.390 \pm 200$ a $1.070 \pm 160$ anos AP $(5.043-3.953$ a $939-364 \mathrm{cal}$ anos AP, segundo ANGULO et al. 2006). Considerando a problemática apresentada, o objetivo do presente trabalho é investigar a geocronologia das cristas de praia do delta atual, a partir do método da Luminescência Opticamente Estimulada. Nesse sentido, espera-se que os resultados possam contribuir na discussão sobre novos aspectos evolutivos da planície costeira e sobre a utilização das cristas de praia como paleoindicadores do nível relativo do mar.

\section{2. Área de Estudo}

O delta do rio Paraíba do Sul está localizado na região do Norte Fluminense (RJ), abarcando principalmente os municípios de Campos dos Goytacazes, São João da Barra e São Francisco do Itabapoana. Essa feição deposicional faz parte do CDRPS, que foi definido como um conjunto de ambientes sedimentares associados à diversas fases de deltação do rio Paraíba do Sul (DIAS, 1981; SILVA, 1987; ROCHA et al. 2013; VASCONCELOS et al. 2016).

Ao sul do Cabo de São Tomé, a planície costeira é formada por cristas de praia de idade pleitocênica (ROCHA et al. 2013) e por uma morfoestratigrafia associada a um ambiente regressivo (ROCHA et al. 2017). Já ao norte do Cabo de São Tomé, encontra-se a planície deltaica, cujas cristas de praia são registros da sedimentação do rio Paraíba do Sul durante o Holoceno, atrelada às condições de diminuição do nível relativo do mar nos últimos 5.500 anos (DOMINGUEZ et al. 1981; ANGULO et al. 2006; DIAS \& KJERFVE, 2009). As cristas de praia que compõe o flanco sul do delta atual estão limitadas por depósitos flúvio-lagunares, enquanto que as cristas do flanco norte estão limitadas pelos Tabuleiros do Grupo Barreiras (figuras 1 e 2).

Em ambos os flancos, as cristas de praia possuem mecanismos de gênese e características fisiográficas diferenciadas, decorrente do desenvolvimento assimétrico que pode ser típico em deltas dominados por ondas (BHATTACHARYA \& GIOSAN, 2003; VASCONCELOS et al. 2016). De acordo com Ashton e Murray (2005) e Ashton e Giosan (2011), quando a hidrodinâmica estiver associada a ocorrência de ondas antidifusivas, isto é, ondas que se aproximam com grande grau de obliquidade em relação à linha de costa, a feição deltaica tenderá a uma morfologia assimétrica, com o desenvolvimento de cristas de praia típicos de deltas dominados por ondas num flanco, enquanto que em outro flanco, poderão ser geradas feições de instabilidade como barras submarinas, spits e lagunas.

No caso do delta do rio Paraíba do Sul, o flanco norte é formado por uma sucessão de cristas de praia, intercaladas com depressões onde são comuns a presença de brejos, manguezais e lagunas. Essa configuração é decorrente do mecanismo de gênese dessas cristas, que estão associadas a emersão de barras submarinas próximas à foz e posterior desenvolvimento de spits, conforme foi descrito detalhadamente por Vasconcelos et al. (2016). Já o flanco sul, apresenta sucessivos sistemas de cristas de praia com direção predominante NE-SW e depressões alongadas menos expressivas do que as do flanco norte. As cristas estão separadas entre si por truncamentos erosivos e por escalonamentos. Tais características representam um hiato de deposição na sequência de progradação deltaica, associado a períodos de erosão costeira (DIAS, 1981; BASTOS, 1997; ROCHA et al. 2017; ROCHA et al. 2018). 
Quanto aos aspectos relativos à dinâmica costeira, Souza et al. (2015) ressaltam a complexidade do espectro de ondas que se propaga na respectiva área de estudo. A atuação do Anticiclone do Atlântico Sul e dos Sistemas Frontais geram um padrão bimodal de propagação de ondas que podem ser predominantemente oriundas de E/NE e do quadrante $\mathrm{S} / \mathrm{SE}$, respectivamente.
(SOUZA, 2011; VASCONCELOS, et al. 2016). A altura média da onda tende a ser em torno de $1,6 \mathrm{~m}$, embora ondas que superam $4,0 \mathrm{~m}$ também podem ser observadas quando estão associadas à passagem de Sistemas Frontais (SOUZA et al. 2015). Já a amplitude da maré é de aproximadamente $1,3 \mathrm{~m}$ no caso de uma maré sizígia, configurando um padrão de micromaré.

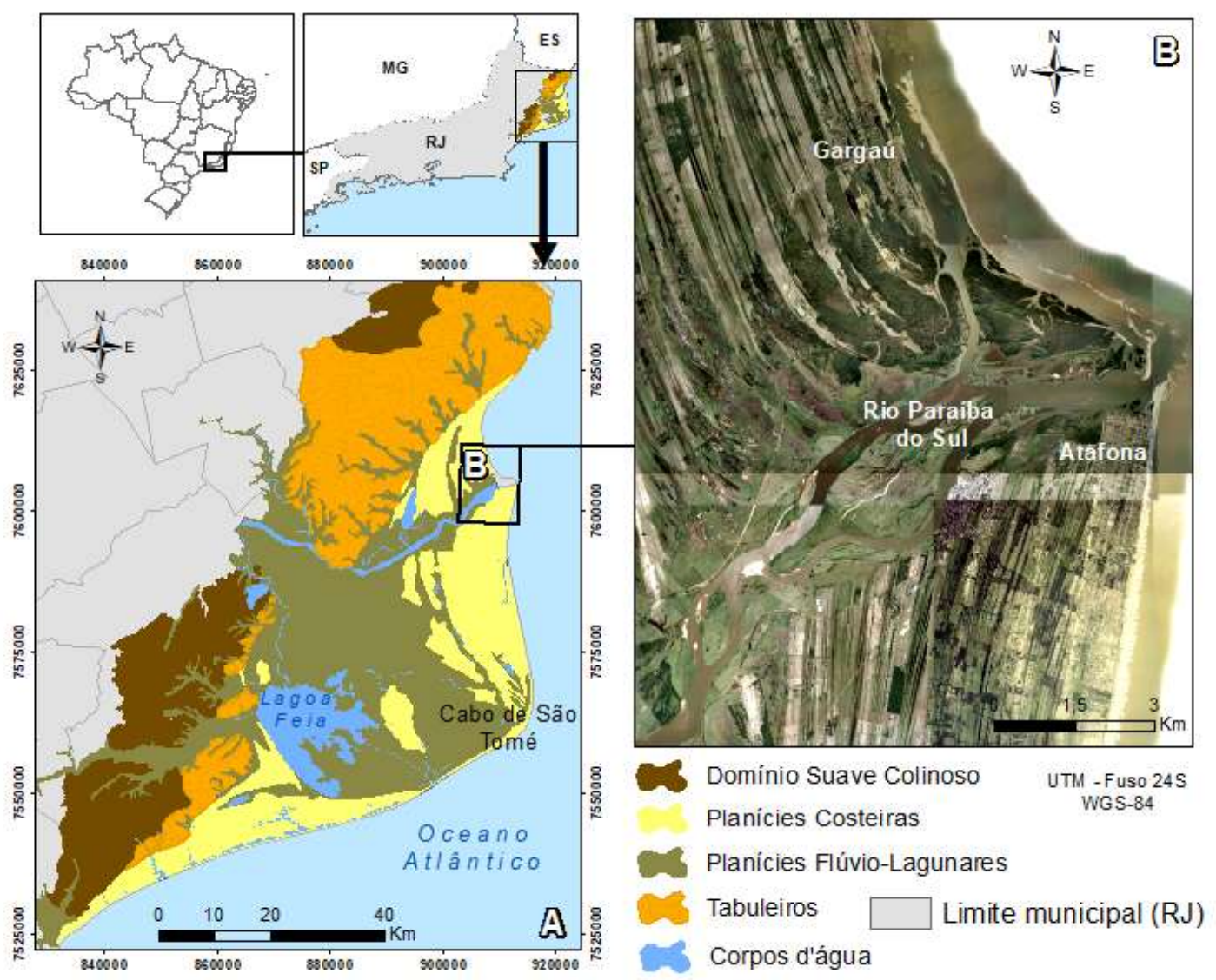

Figura 1 - (A) Localização e geomorfologia (modificado do CPRM) do Complexo Deltaico do rio Paraíba do Sul (CDRPS). Ao sul do Cabo de São Tomé, encontra-se o setor meridional, formado por cristas de praia pleistocênicas e uma barreira transgressiva holocênica (ROCHA et al. 2013). Ao norte do Cabo de São Tomé, encontra-se o delta atual de construção holocênica. (B): Destaque para as cristas de praia do delta do rio Paraíba do Sul. No flanco sul podem ser observadas as diferenças nos alinhamentos entre as cristas, que são separados por truncamentos erosivos. No flanco norte, é possivel visualizar a presença de spits, pequenas lagoas em processo de colmatação e largas depressões preenchidas por manguezais e brejos.

\section{Materiais e Métodos}

Para investigar as idades das cristas de praia pelo método da LOE, foram coletadas 10 amostras no flanco sul do delta e 11 amostras no flanco norte (figura 2), totalizando 21 amostras cujas coordenadas estão na tabela 1. Cabe ressaltar que, no flanco sul, quatro amostras foram coletadas bem próximas umas das outras entre truncamentos erosivos (S4 e S5; S6 e S7) com a intenção de analisar o intervalo temporal entre o período de erosão costeira (ou hiato de deposição) e a retomada da progradação da planície (figuras $2 \mathrm{~B}$ e $2 \mathrm{C}$ ).

As coletas foram realizadas em trincheiras de aproximadamente $1,0 \mathrm{~m}$ de profundidade, onde foram inseridos tubos de alumínio que, após a retirada, foram devidamente vedados para evitar a entrada de luz. As amostras foram enviadas para o Laboratório Datação, 
Comércio e Prestação de Serviços LTDA, localizado na cidade de São Paulo, onde foram submetidas a uma série de procedimentos padrões. Primeiramente, foi realizado um tratamento químico com $\mathrm{H}_{2} \mathrm{O}_{2}(20 \%)$, $\mathrm{HF}(20 \%)$ e $\mathrm{HCl}(10 \%)$; posteriormente, foi separada uma fração granulométrica na faixa de $100-160 \mu \mathrm{m}$ a partir da técnica de peneiramento. Foram utilizadas 15 alíquotas para cada amostra, que sofreram estímulos com luz. Para a obtenção das idades foi aplicado o Protocolo SAR, que foi formalizado Murray e Wintle (2000) e tem sido o procedimento mais utilizado até o momento.

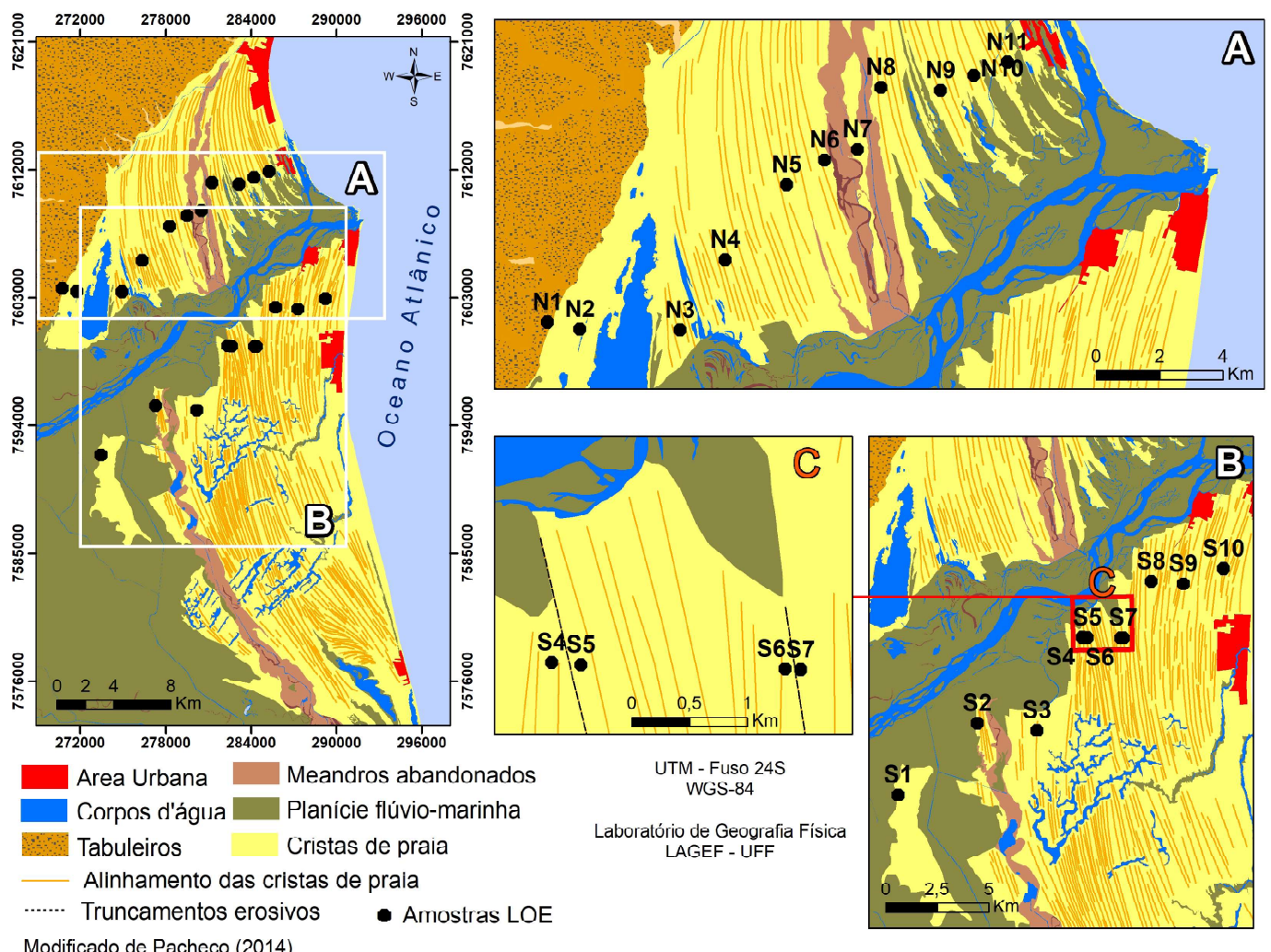

Figura 2 - Localização das amostras coletadas para a análise da geocronologia pelo método da LOE. (A) Localização das amostras no flanco norte. (B) Localização das amostras no flanco sul. (C) Localização das amostras coletadas em cristas de praia adjacentes a dois truncamentos erosivos no flanco sul do delta.

Em cada trincheira aberta para a coleta das amostras buscou-se estimar a altura ortométrica do respectivo ponto da planície através do GPS Geodésico de dupla frequência, modelo GTR-G2 da TechGeo. Os dados foram pós-processados no programa GTR Processor com os dados da Rede Brasileira de Monitoramento Contínuo dos Sistemas GNSS (RBMC), utilizando a estação de Campos dos Goytacazes (RJCG). A altura ortométrica foi obtida a partir da correção do Modelo de Ondulação Geoidal pelo programaMAPGEO.

Também foram realizados transectos topográficos ao longo da planície a fim de verificar se a morfologia das cristas de praia se ajusta as curvas de variações do nível relativo do mar de Martin et al. (1997) e Angulo et al. (2006). Esses transectos não foram contínuos ao longo da planície, devido a questões de acesso e obstáculos, como a presença de lagoas, brejos e manguezais. Primeiramente, pontos de controle altimétrico foram estabelecidos com o GPS Geodésico e a topografia foi realizada com auxílio de Estação Total modelo Trimble 5500Series. As distâncias vertical e horizontal indicadas pela Estação Total para cada ponto foram anotadas em cadernetas de nivelamento topográfico e posteriormente processadas em gabinete no programa Excel for Windows para obtenção de gráficos e análise de variações observadas nos transectos. 
Tabela 1: Coordenadas das amostras coletadas e as respectivas altitudes ortométricas.

\begin{tabular}{|c|c|c|c|c|}
\hline Código datação & Amostra LOE & Long (WGS-84) & Lat (WGS-84) & Fuso UTM \\
\hline 4441 & S1 & 273451 & 7591903 & $24 \mathrm{~K}$ \\
\hline 4442 & S2 & 277297 & 7595399 & $24 \mathrm{~K}$ \\
\hline 4443 & S3 & 280182 & 7595053 & $24 \mathrm{~K}$ \\
\hline 4444 & S4 & 282384 & 7599574 & $24 \mathrm{~K}$ \\
\hline 4445 & S5 & 282622 & 7599558 & $24 \mathrm{~K}$ \\
\hline 4446 & S6 & 284265 & 7599542 & $24 \mathrm{~K}$ \\
\hline 4448 & S7 & 284389 & 7599538 & $24 \mathrm{~K}$ \\
\hline 4449 & S8 & 285733 & 7602296 & $24 \mathrm{~K}$ \\
\hline 4450 & S9 & 287296 & 7602179 & $24 \mathrm{~K}$ \\
\hline 4451 & S10 & 289243 & 7602917 & $24 \mathrm{~K}$ \\
\hline 4452 & N1 & 270743 & 7603647 & $24 \mathrm{~K}$ \\
\hline 4453 & N2 & 271763 & 7603420 & $24 \mathrm{~K}$ \\
\hline 4454 & N3 & 274924 & 7603398 & $24 \mathrm{~K}$ \\
\hline 4455 & N4 & 276359 & 7605617 & $24 \mathrm{~K}$ \\
\hline 4456 & N5 & 278300 & 7607997 & $24 \mathrm{~K}$ \\
\hline 4457 & N6 & 279499 & 7608764 & $24 \mathrm{~K}$ \\
\hline 4458 & N7 & 280529 & 7609112 & $24 \mathrm{~K}$ \\
\hline 4447 & N8 & 281270 & 7611056 & $24 \mathrm{~K}$ \\
\hline 4459 & N9 & 283162 & 7610969 & $24 \mathrm{~K}$ \\
\hline 4460 & N10 & 284208 & 7611451 & $24 \mathrm{~K}$ \\
\hline 4461 & N11 & 285265 & 7611861 & $24 \mathrm{~K}$ \\
\hline
\end{tabular}

\section{Resultados e Discussões}

\subsection{Geocronologia e implicações na construção da planície} costeira do delta do rio Paraíba do Sul

Praticamente todas as idades encontradas são holocênicas, estando entre $4.130 \pm 580$ anos e $350 \pm 70$ anos conforme era esperado, considerando os trabalhos pretéritos que utilizaram idades estabelecidas por Radiocarbono como Silva (1987), Martin et al. (1997) e Moreira (1998). Porém, as datações das cristas de praia propriamente dita, e não de elementos secundários como conchas presentes nas cristas e nas lagoas, mostraram algumas diferenças dos modelos pretéritos de evolução do delta e suscitaram novas questões.

Apesar da maior parte das amostras serem posteriores ao Máximo Transgressivo do Holoceno (aproximadamente 5.500 anos), foram encontradas as idades de $38.650 \pm 3.170$ anos (N1) e $9.400 \pm 1.300$ anos (N2). A amostra N1 foi coletada próximo ao contato entre o Grupo Barreiras e a planície costeira (figura 2) e cabe ressaltar que não havia até o momento registros de idades pleistocênicas na área de influência do delta atual do CDRPS. Idades pleistocênicas, em torno de 80.000 anos, foram encontradas por Rocha et al. (2013), somente no setor meridional do CDRP, nas cristas de praia próximo ao município de Quissamã, no interior do Parque Nacional de Restingas de Jurubatiba. Nesse sentido, a idade da amostra N1 pode indicar uma maior complexidade a ser explorada na história de evolução Quaternária da respectiva área.

Já a amostra N2 foi coletada próxima à margem interna da Lagoa do Campelo. De acordo com Martin et al. (1984, 1997), essa lagoa foi formada durante o Holoceno, a partir da colmatação de um antigo sistema lagunar mais amplo. As idades encontradas por Da Luz et al. (2006), entre 2.800 e 2.300 anos AP, corroboram essa idade holocênica. Nesse sentido, é provável que a amostra N2 seja correspondente ao "Estádio A" de Martin et al. (1993), anterior há 5.100 anos AP. De acordo com os autores, durante a transgressão do Holoceno havia um grande sistema barreira-laguna há pelo menos 7.000 anos AP. Nesse sentido, é provável que esses cordões arenosos sejam o registro dessa fase transgressiva e do aumento do nível do mar após o último máximo glacial. 
Tabela 2: Idades numéricas das cristas de praia obtidas pelo método da LOE no delta do rio Paraíba do Sul.

\begin{tabular}{|c|c|c|c|c|c|}
\hline Amostra LOE & $\begin{array}{c}\text { Dose Anual } \\
\text { (Gy/ano) }\end{array}$ & $\mathbf{P}$ (Gy) & Desvio Padrão (P) & Idade (anos) & $\begin{array}{c}\text { Altitude } \\
\text { ortométrica (m) }\end{array}$ \\
\hline S1 & $1.100 \pm 95$ & 3,1 & 0,9 & $\mathbf{2 . 8 6 0 \pm 3 9 0}$ & 4,721 \\
\hline S2 & $970 \pm 70$ & 2,7 & 0,8 & $\mathbf{2 . 7 9 0 \pm 3 4 0}$ & 3,921 \\
\hline S3 & $900 \pm 35$ & 1,9 & 0,4 & $\mathbf{2 . 1 0 0 \pm 1 9 0}$ & 4,53 \\
\hline S4 & $915 \pm 175$ & 1,3 & 0,5 & $\mathbf{1 . 4 2 0 \pm 3 4 0}$ & 4,541 \\
\hline S5 & $2.350 \pm 240$ & 3,1 & 0,6 & $\mathbf{1 . 3 2 0 \pm 2 0 0}$ & 4,592 \\
\hline S6 & $1.615 \pm 200$ & 1,4 & 0,1 & $\mathbf{8 7 0 \pm 1 5 0}$ & 1,976 \\
\hline S7 & $850 \pm 90$ & 0,8 & 0,2 & $\mathbf{9 5 0 \pm 1 4 5}$ & 2,257 \\
\hline S8 & $1.610 \pm 100$ & 1,3 & 0,3 & $\mathbf{8 1 0 \pm 9 0}$ & 2,344 \\
\hline S9 & $1.680 \pm 200$ & 1,0 & 0,1 & $\mathbf{6 0 0 \pm 1 0 0}$ & 2,589 \\
\hline S10 & $1.000 \pm 155$ & 0,35 & 0,1 & $\mathbf{3 5 0} \pm \mathbf{7 0}$ & 0,989 \\
\hline N1 & $780 \pm 25$ & 30,2 & 4,0 & $\mathbf{3 8 . 6 5 0 \pm 3 . 1 7 0}$ & 3,972 \\
\hline N2 & $1.940 \pm 175$ & 18,2 & 4,3 & $\mathbf{9 . 4 0 0 \pm 1 . 3 0 0}$ & 3,904 \\
\hline N3 & $1.940 \pm 175$ & 8,0 & 0,6 & $\mathbf{4 . 1 3 0 \pm 5 8 0}$ & 3,956 \\
\hline N4 & $2.250 \pm 160$ & 7,2 & 0,7 & $\mathbf{3 . 2 0 0 \pm 3 8 0}$ & 5,417 \\
\hline N5 & $3.250 \pm 230$ & 8,4 & 1,8 & $\mathbf{2 . 5 8 0 \pm 3 1 0}$ & 4,259 \\
\hline N6 & $2.970 \pm 400$ & 5,8 & 0,9 & $\mathbf{1 . 9 6 0 \pm 3 6 0}$ & 2,572 \\
\hline N7 & $915 \pm 65$ & 1,5 & 0,4 & $\mathbf{1 . 6 4 0 \pm 2 0 0}$ & 3,462 \\
\hline N8 & $1.695 \pm 220$ & 1,8 & 0,4 & $\mathbf{1 . 0 6 0 \pm 1 9 0}$ & 1,441 \\
\hline N9 & $1.700 \pm 185$ & 1,2 & 0,2 & $\mathbf{7 1 0} \pm \mathbf{1 1 0}$ & 0,569 \\
\hline N10 & $1.800 \pm 200$ & 0,9 & 0,1 & $\mathbf{5 0 0 \pm 8 0}$ & 1,668 \\
\hline N11 & $2.270 \pm 300$ & 0,7 & 0,1 & $\mathbf{3 1 0 \pm 5 5}$ & 0,595 \\
\hline
\end{tabular}

A amostra N3, de idade 4.130580 anos, marca o início da construção da planície de cristas de praia, já na fase de diminuição do nível relativo do mar após o Máximo Transgressivo do Holoceno há 5.500 anos AP (MARTIN et al. 1997; ANGULO et al. 2006). No flanco norte, as idades vão decrescendo em direção ao mar até a amostra N11, com idade 31055 anos, resultando numa taxa de progradação de aproximadamente $3,2 \mathrm{~m} /$ ano. Destaca-se que essa taxa não foi linear no tempo. Entre as amostras N9 e N11, entre $710 \pm 110$ e 31055 anos, essa taxa de progradação passou a ser mais acentuada, ficando em torno de 5,0 m/ano. Cabe ressaltar que nesse flanco não houve inversão de idades e o desvio padrão das Paleodoses das alíquotas utilizadas para análise são menores que 5Gy. Esse valor, segundo Clarke et al. (1999), é considerado o limite que indica pouca probabilidade de existir sinal residual de luminescência nas amostras, o que poderia gerar idades superestimadas.

Ao comparar as idades obtidas por radiocarbono de Martin et al. (1993) e as idades obtidas por LOE do presente trabalho, é possível observar que a algumas idades estabelecidas próximos ao mesmo alinhamento entre as cristas de praia foram um pouco mais antigas quando estabelecidas pelo Radiocarbono, como as amostras relativas as idades $1.980 \pm 90$ e $4.390 \pm 200$ anos AP (respectivamente comparadas às de $1.640 \pm 200$ e $2.580 \pm 310$ anos), conforme mostra a figura 3. Como as conchas foram o material para a datação, é provável que estas tenham sofrido retrabalhamento antes da deposição, o que pode resultar em idades mais antigas para a formação do depósito sedimentar (figura 3). Porém em ambos os métodos, as idades encontradas corroboram o fato de que a progradação da planície iniciou a cerca de 4.000 anos AP., quase 1.200 anos após o Máximo Transgressivo do Holoceno.

Associando a topografia das cristas de praia com as idades, pode ser verificada uma diminuição da altimetria dessas feições a medida que as idades vão ficando mais jovens acompanhando, portanto, a diminuição relativa do nível do mar. Essa relação é mais facilmente observada no flanco norte, visto que há mais transectos do que foi possível realizar no flanco sul (figura 4). Nesse sentido, a progradação dessa planície, a partir da incorporação das cristas de praia, possui uma componente de regressão forçada ainda que nesse artigo não sejam mostrados dados de subsuperfície relacionados à estratigrafia e arquitetura deposicional. 


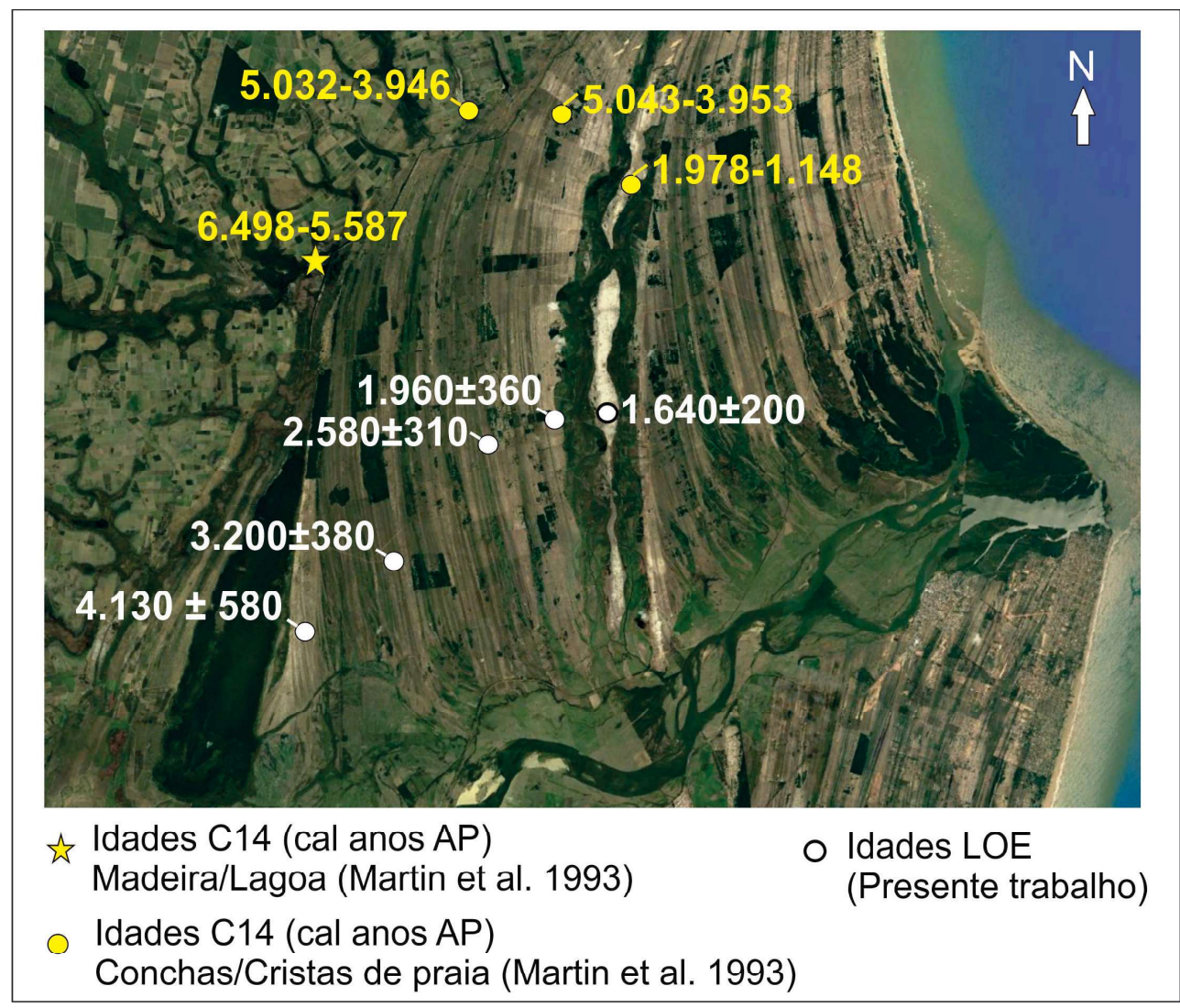

Figura 3 - Comparação entre as idades obtidas por LOE no presente trabalho e as idades obtidas por Radiocarbono, por Martin et al. (1993). Foram utilizadas as idades calibradas por Angulo et al. (2006).

No caso das idades do flanco sul, as duas amostras mais interiorizadas ( $\mathrm{S} 1$ e S2) possuem idades de $2.860 \pm 390$ e $2.790 \pm 340$, respectivamente (figura 2 e tabela 2). Nesse caso, é provável que os registros mais antigos, de cerca de 4.000 anos como a amostra $\mathrm{N} 3$, não tenham sido preservados em função das fases erosivas que ocorrem no flanco sul, cujas evidências são os truncamentos nos alinhamentos das cristas de praia e os escalonamentos próximos ao rio Paraíba do Sul. Uma segunda hipótese é a de que essas duas amostras tenham sofrido algum retrabalhamento associado a dinâmica fluvial, visto que elas se encontram bem próximas à classe geomorfológica da planície fluvio-marinha e de uma série de meandros abandonados (figura 2). Diferentemente do flanco norte, em que o domínio costeiro se inicia no contato com o Grupo Barreiras; no flanco sul, o início do domínio costeiro pode não ser claramente identificado através de mapeamentos geomorfológicos.

As amostras $\mathrm{S} 4$ e S5, que estão no limite de um truncamento erosivo, possuem idades de $1.420 \pm 340$ e 1.320 \pm 200 anos; enquanto que as amostras S6 e S7, possuem idades de $870 \pm 150$ e $950 \pm 145$ anos. Essas duas últimas amostras mostraram uma sutil reversão, embora estejam dentro da margem de erro (figura $2 \mathrm{C}$ e tabela 2). Essas idades mostram que o período de erosão costeira pode ultrapassar um século, embora mais amostras precisem ser coletadas para essa avaliação mais específica.

Ainda assim, os dados recentes sobre a erosão costeira no distrito de Atafona, localizada no flanco sul do delta, indicam que pelo menos desde 1954, esse processo tem ocorrido nesse litoral. Isso foi observado a partir de fotografias aéreas antigas por Santos (2006). Já Rocha et al. (2018), a partir do monitoramento de perfis de praia nos últimos 15 anos, estimaram uma taxa de $3,2 \mathrm{~m} /$ ano de erosão costeira. De acordo com Azevedo (2004) e Mello et al. (2018), mais de 200 construções foram perdidas e mais de 20 quadras foram afetadas entre 1975 e 2016. Apesar disso, os resultados das idades nos truncamentos erosivos indicam que esse processo tende a cessar na escala secular, uma vez que esses registros representam um hiato no processo de progradação da planície. Essa informação pode ser bastante relevante 
caso seja aplicada com intuito de avaliar e pensar ações de mitigação para o problema da erosão costeira na cidade de Atafona. Ainda assim, cabe destacar que o entendimento sobre a escala temporal desse processo pode ser alterado considerando os possíveis cenários de aumento do nível médio do mar nesse século e demais consequências associadas as mudanças climáticas (RANASINGHE, 2016).

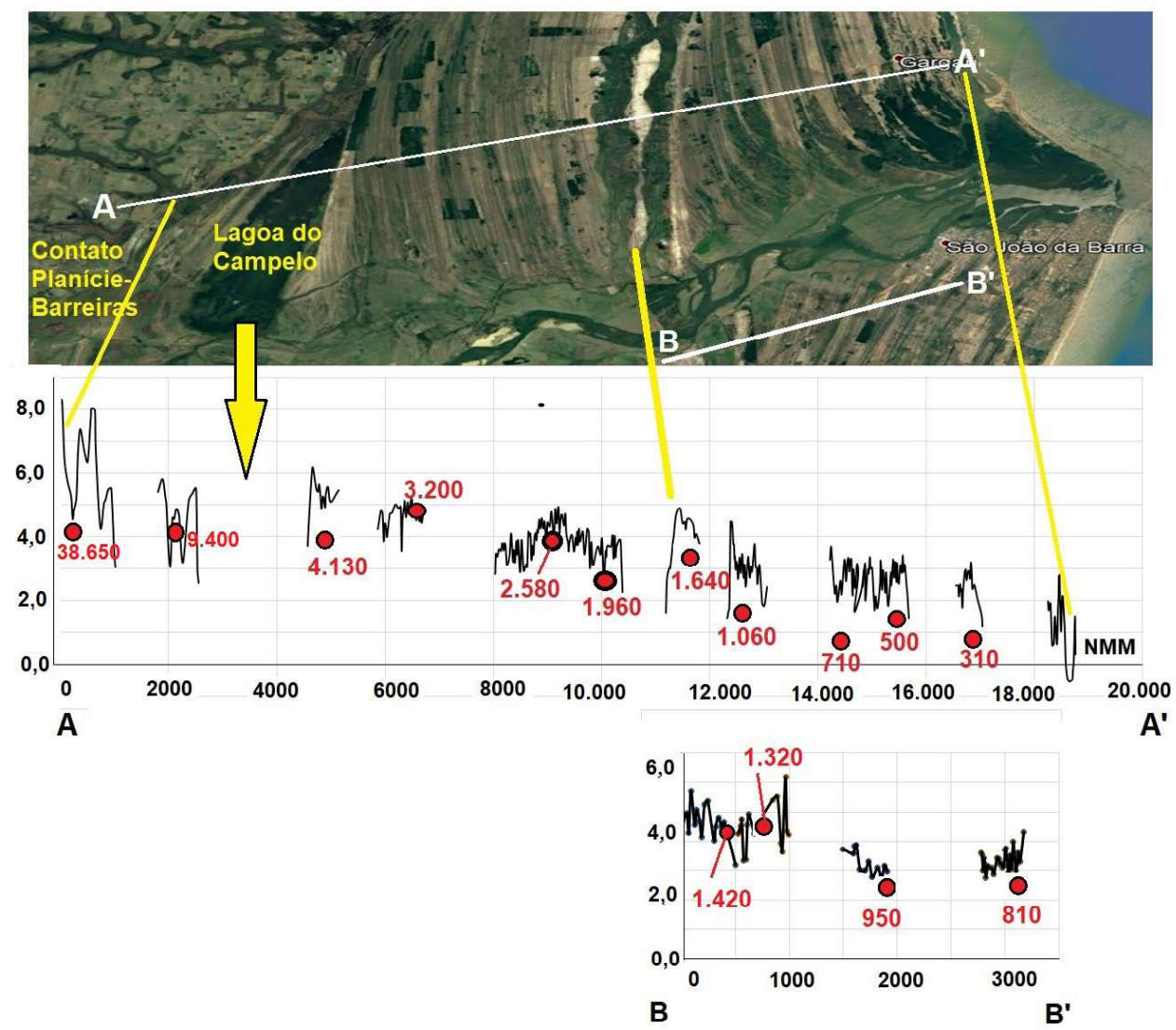

Figura 4 - Transectos nos flancos norte e sul do delta, com as respectivas idades correlacionadas pelo princípio da continuidade lateral entre as cristas de praia. Notar a diminuição da altimetria das cristas do flanco norte em direção ao mar, indicando uma componente de regressão forçada na progradação da planície, nos últimos 4.000 anos aproximadamente.

Em termos de taxa de progradação, o flanco sul também não apresentou uma taxa linear ao longo do tempo. Entre as amostras S2 e S6, a taxa de progradação variou entre 3 e $4 \mathrm{~m} /$ ano aproximadamente. Já a partir da amostra S7 até a S10, em torno de 950 até 350 anos, a velocidade de progradação foi mais rápida, ficando em torno de 7,5 $\mathrm{m} /$ ano. Esse aumento da velocidade nos últimos 1000 anos também foi observado no flanco norte, ainda que com uma taxa menor.

De acordo com as idades estabelecidas por LOE, a construção holocênica da planície no flanco Sul parece ter sido mais rápida do que no flanco norte. Nesta última a taxa média ficou em torno de $3,0 \mathrm{~m} / \mathrm{ano}$ e no flanco sul, em torno de 5,0 m/ano. Trabalhos pretéritos que investigaram a dinâmica de transporte sedimentar no CDRPS, como
Cassar e Neves (1993), Machado (2009) e Vasconcelos et al. (2016), identificaram que predominantemente há uma divergência na direção do transporte sedimentar a partir da foz, sendo preferencialmente de sul para o norte, no flanco norte; e de norte para o sul, no flanco sul. De acordo com os autores, isso indica que a rio Paraíba do Sul contribui na construção da planície no caso dos dois flancos.

Contudo, os resultados de Cassar e Neves (1993) também mostram uma componente de transporte sedimentar de sul para norte, a partir do Cabo de São Tomé (figura 1) em direção ao flanco sul do delta. Nesse sentido, é possível que a construção da planície no flanco sul tenha uma segunda fonte sedimentar além do rio Paraíba do Sul, o que explicaria a taxa de progradação mais acentuada nesse mesmo flanco. 
4.2 Cristas de praia como paleoindicadores de variações do nível do mar

De acordo com Angulo e Souza (2014), os paleoníveis marinhos podem ser inferidos a partir de diferentes tipos de indicadores, onde destacam-se os de origem geomorfológica, faciológica, biológica e arqueológica; além dos associados a microfósseis e fracionamento isotópico. No caso das cristas de praia, elas se encaixam na origem geomorfológica, do tipo deposicional, juntamente com os demais terraços marinhos e lagunares.

Independentemente do tipo de indicador, Angulo e Souza (2014) ressaltam que é muito importante determinar a altura do indicador em relação ao análogo moderno, a fim de determinar o nível de referência para o nível médio do mar. Como as cristas de praia representam antigas paleopraias que foram construídas por processos de espraiamento da ação das ondas (OTVOS, 2000; NIELSEN et al. 2006; TAMURA, 2012), esse análogo deve ser a praia atual. Nesse caso, espera-se que as cristas de praia mostrem uma diminuição da altimetria das amostras coletadas conforme o nível do mar diminui após o Máximo Transgressivo do Holoceno, inicialmente demonstrado na figura 4.

Essa correlação também pode ser observada na fi- gura 5A. Porém, ao comparar as amostras do flanco norte e do flanco sul, é possível observar que essa correlação é um pouco mais linear no flanco norte, assim como as altimetrias das amostras são um pouco mais baixas quando comparadas às amostras do flanco sul. Essas diferenças podem ser explicadas por seus respectivos análogos modernos. No flanco sul, as cristas de praia podem apresentar um capeamento eólico e até mesmo assumir a forma de dunas frontais, conforme pode ser observado na figura $5 \mathrm{~B}$.

$\mathrm{Na}$ topobatimetria do perfil praial relativo ao flanco sul, a crista da berma alcança a cota de 2,5 m relação ao nível médio do mar, enquanto que o topo das dunas frontais alcança cerca de 4,0 m (figura 5B). Essa diferença resulta num pacote eólico de cerca de 1,5 m. Considerando que as amostras foram coletadas acerca de $1,0 \mathrm{~m}$ da superfície, é possível que o paleoindicador não seja representativo do ambiente praial e, portanto, o nível de referência não seja efetivamente o nível médio do mar, o que explicaria a altimetria mais alta das amostras do flanco sul e a menor correlação entre a diminuição das idades e da altimetria das amostras (figura 5A). Tamura (2012) e Angulo e Souza (2014) já haviam chamado a atenção para essa questão do capeamento eólico sobre as cristas de praia poder interferir na análise dessas feições como paleoindicadores geomorfológicos.

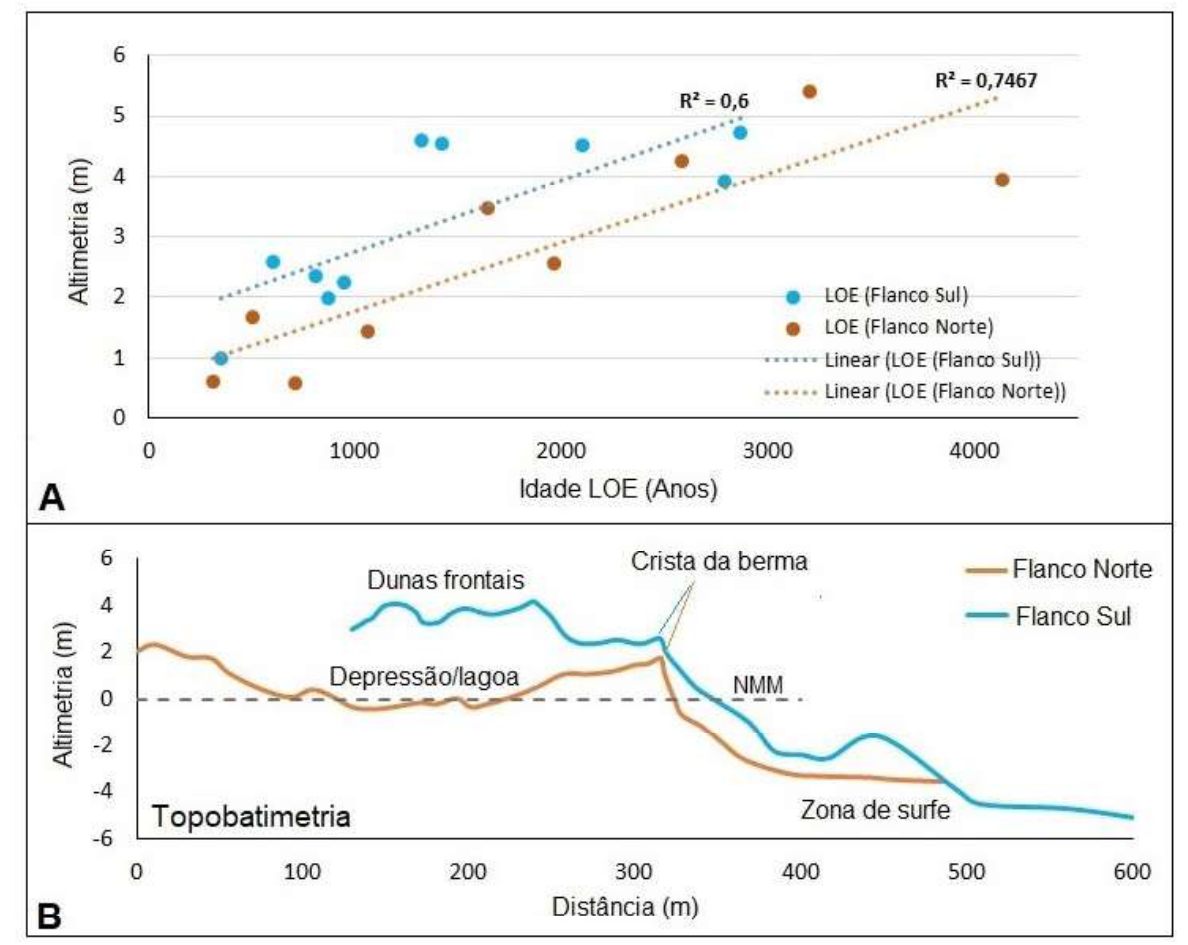

Figura 5 - (A) Correlação entre a idade das amostras e a altimetria das mesmas. As amostras do flanco sul apresentam uma correlação ligeiramente menor, provavelmente associado a presença de cobertura é́lica nas cristas de praia. (B) Análogos modernos das cristas de praia no delta do rio Paraíba do Sul. A cobertura eólica mencionada pode ser observada no análogo das cristas de praia e do perfil praial do flanco sul. No flanco norte, a berma é cerca de 0,5 $\mathrm{m}$ menor do que a do flanco sul. 
Cabe destacar que, dependendo da localização no delta, essas dunas podem atingir até $12 \mathrm{~m}$ de altitude (ROCHA et al. 2018). Esses casos mais excepcionais de atividade eólica ocorrem na praia atual, bem próxima a foz, restrita a área de erosão costeira no distrito de Atafona. A erosão do perfil praial têm liberado uma quantidade significativa de sedimentos que tendem a ser transportados pelos ventos de $\mathrm{NE}$, e incorporados às dunas costeiras (ROCHA et al. 2018). Nesse sentido, avaliar as cristas de praia do flanco sul como paleoindicador no nível do mar, ainda deve exigir a investigação do contato entre o eólico e o praial a partir de perfis de GPR na localização das amostras, conforme foi realizado por Rocha et al. (2013).

Já no caso do análogo do prisma praial do flanco norte, é possível notar que a crista da berma é ligeiramente mais baixa, com altimetria em torno de $2,0 \mathrm{~m}$ em relação ao nível médio do mar (figura 5B). De acordo com Vasconcelos et al. (2016), as cristas de praia no flanco norte podem ter origem associada a emersão de barras submarinas. Quando essas barras emergem, podem formar spits que são deslocados em direção ao continente para serem incorporados à planície costeira, através de mecanismos de transposição de ondas. Esse processo ocorre devido à baixa altimetria do spit, que permite que as ondas ultrapassem a crista da barreira arenosa. Além disso, a característica refletiva da praia, formada por sedimentos grossos, inibe a atividade eólica e a formação de dunas no flanco norte do delta.

A diferença das altimetrias entre o pós-praia e a zona de estirâncio, isto é, entre a base da duna (ou limite de vegetação) e entre o nível do mar na maré baixa de sizígia (SOUZA et al. 2005), pode oferecer uma estimativa de espessura sedimentar referente ao que seria a deposição praial e, portanto, pode fornecer uma ideia de margem de precisão. No caso do análogo do flanco norte, essa margem se dá em torno de $\pm 2,5 \mathrm{~m}$; e no caso do flanco sul, em torno de $\pm 3,2 \mathrm{~m}$. Esses valores são condizentes aos encontrados por Rocha et al. (2013), para o caso das cristas de praia em Quissamã, também localizados no CDRPS. Através de GPR e sondagens, os autores definiram a espessura da deposição praial (pós-praia e zona de estirâncio) entre 2,5 $\mathrm{m}$ e 3,0 m. Cabe ressaltar que essa margem pode ainda ser maior, considerando questões como altura das ondas e o tipo de morfodinâmica de praia, uma vez que a granulometria e a energia das ondas estão relacionadas à altura da berma (SHORT, 1999).

\subsection{Paleoníveis marinhos e curvas de variações do nível do mar}

As idades obtidas pelo método da LOE permitem a discussão de interessantes questões com relação às variações do nível do mar entre o Pleistoceno Superior e o Holoceno. Feições deposicionais costeiras com idades próximas da amostra N1, $38.650 \pm 3.170$ anos, não costumam estar preservadas visto que, de acordo com as curvas de estágio isotópico, o nível do mar estaria entre $-85 \mathrm{~m}$ e $-55 \mathrm{~m}$ abaixo do nível médio do mar, caracterizando o Estágio Marinho Isotópico 3 (MIS 3), no intervalo entre 60 e 25 mil anos atrás (SHACKLETON, 2000; LAMBECK AND CHAPPELL, 2001; RABINEAU et al. 2006), conforme mostra a figura 6.

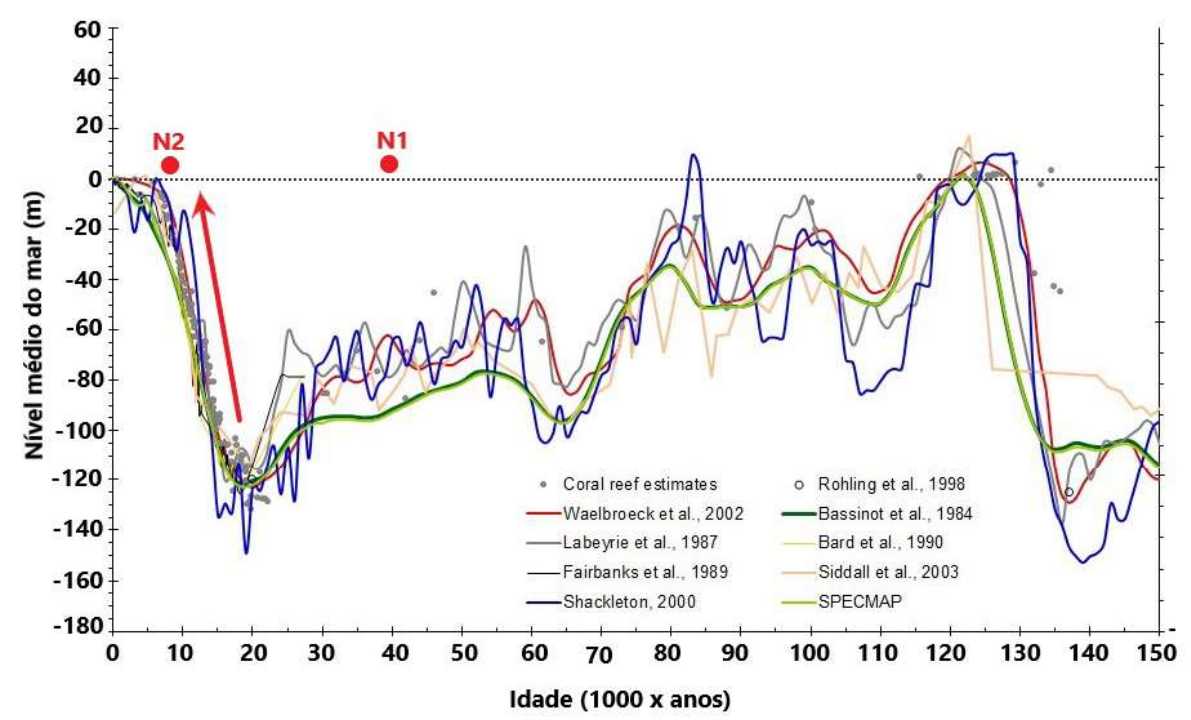

Figura 6 - Localização espaço-temporal das amostras N1 e N2 no envelope de curvas de variações do nível do mar entre o Pleistoceno Tardio e o Holoceno a partir de publicações pretéritas, sintetizados por Rabineau et al. (2006). O paleonivel representado pela amostra N1 encontra-se bastante acima do nivel médio do mar esperado para cerca de 40.000 anos atrás. Já o paleonivel N2, provavelmente representa a fase transgressiva posterior ao Último Máximo Glacial, conforme Martin et al. (1993) já havia apontado. 
Porém, recentemente, Dillenburg et al. (2019) sugerem que os registros sedimentares relativos ao MIS 3 podem estar posicionados entre $-5 \mathrm{~m}$ e $-23 \mathrm{~m}$ abaixo do nível médio atual, no caso do litoral sul do Brasil. Salvaterra et al. (2017) também identificaram registros transgressivos do mesmo Estágio Isotópico Marinho entre - 7 m e -19 m abaixo do nível médio atual, na Baixada Santista. Já Silva et al. (2014) verificaram na planície costeira de Maricá, no litoral fluminense, que uma sequencia transgressiva teria começado a se desenvolver por volta de 47.000 anos AP, cujos registros encontram-se a aproximadamente -15 $\mathrm{m}$ abaixo do nível médio do mar.

Especificamente no caso de planícies deltaicas, Cohen et al. (2014) e Rossetti et al. (2015) também encontraram cristas de praia relativos aos Estágios Isotópicos Marinhos 3 e 2 (MIS 3 e 2) no delta do rio Doce, a partir de datações por radiocarbono e LOE. Rossetti et al. (2015) associaram essas cristas a uma fase de progradação do delta, já no Pleistoceno Tardio. Apesar do MIS 2 representar paleoníveis marinhos de dezenas de metros abaixo do nível médio do mar, os autores argumentaram a possibilidade de que essa diminuição eustática do nível do mar pode ter sido compensada com efeitos de neotectônica. No presente trabalho, é possível que a feição deposicional onde a amostra foi coletada possa não ter origem marinha, visto que ela está bem próxima ao contato do Grupo Barreiras. Nesse sentido, há a necessidade de investigações de subsuperfície como Radar de Penetração do Solo e sondagens.

Com relação as curvas de variações do nível do mar no holoceno, Martin et al. (2003) e Angulo et al. (2006) sugerem que após o Último Máximo Glacial, o nível do mar alcançou o nível médio atual, por volta de 7.000 anos AP. Portanto, idades semelhantes a amostra N2, 9.400 \pm 1.300 anos, também não são comuns de estarem preservadas em áreas emersas. Se, pelas curvas regionais, essa idade estaria a poucos metros abaixo do nível do mar, nesse caso, a possibilidade de compensação por efeitos neotectônicos pode ser aventada. Ainda assim, algumas curvas globais mostram registros acima do nível médio do mar, a partir dos 11.000 anos, conforme mostra a figura 6 (RABINEAU et al. 2006). Cabe ressaltar que Cohen et al. (2014) e Rossetti et al. (2015) também encontraram idades semelhantes à amostra N2, no delta do rio Doce. Essas idades pouco comuns encontradas recentemente em dois deltas do sudeste brasileiro mostram a necessidade de maiores investigações sobre o comportamento do nível do mar no Pleistoceno Tardio, e na transição entre o Pleistoceno/Holoceno.

As demais idades, entre $4.130 \pm 580$ anos e $310 \pm$ 55 anos, refletem interessantes questões quando inseridas nas curvas de Martin et al. (1997, 2003) e Angulo et al. (2006). Essas duas curvas são consideradas as principais referências com relação ao comportamento do nível relativo do mar no holoceno, para a grande parte da costa brasileira. No caso da curva de Martin et al. (1997, 2003), as idades e altimetrias das cristas parecem bem ajustadas a tendência de diminuição relativa nível do mar, a partir de 2.500 anos AP, principalmente no caso das cristas do flanco norte que tendem a não apresentar cobertura eólica (figura 7).

Porém, cabe destacar a questão das oscilações de baixa frequência defendidas por Martin et al. (1997, 2003), cuja argumentação foi muito debatida até o início dos anos 2000 (MARTIN et al., 1998; ANGULO \& LESSA, 1997; ANGULO et al. 2006). Os autores defendiam a ocorrência de duas oscilações de alta frequência, com duração em torno de 300 anos, próximas há 3.800 e 2.700 anos AP, conforme mostra a figura 7 . No presente trabalho, três amostras estão inseridas dentro do intervalo da oscilação de alta frequência de 2.700 anos AP.

De acordo com Martin et al. (1993), no modelo proposto sobre a evolução do delta do rio Paraíba do Sul, esse intervalo entre 2.700 e 2.500 anos AP corresponde ao Estádio E do modelo. Os autores propuseram uma erosão generalizada decorrente da rápida elevação do nível do mar, corroborada por datações de conchas provenientes de uma paleolaguna entre 2.500 anos e 2.400 anos AP. Porém, a presença de cristas de praia preservadas nesse intervalo temporal refuta essa hipótese e, consequentemente, torna pouco provável a ocorrência dessa oscilação de alta frequência na área de estudo.

Angulo et al. (2006) analisaram mais de 1000 amostras que foram datadas por $\mathrm{C}^{14} \mathrm{e}$ que foram publicadas por diferentes autores, com o objetivo de revisar o papel dos indicadores de paleonível do mar. A análise permitiu a consolidação de um modelo de curva de variação do nível do mar para a costa brasileira, durante os últimos 7.000 anos. Além disso, os autores concluíram que a possibilidade de contaminação das amostras e o uso muito diversificado de indicadores datáveis (indicadores biológicos, arqueológicos, geomorfológicos, geológicos) podem gerar uma interpretação equivocada dos dados e consequentemente, uma compreensão também equivocada do comportamento relativo do nível do mar. 


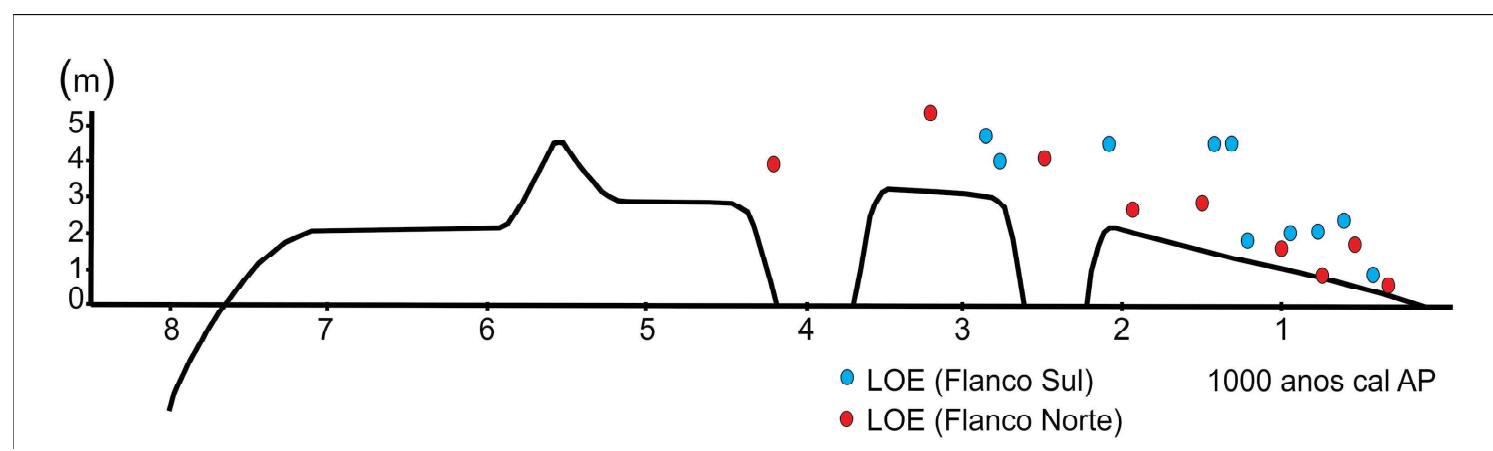

Figura 7 - Localização espaço-temporal das amostras de LOE na curva de variação relativa do nível do mar, construída a partir de idades calibradas por Martin et al. (2003), referente a Salvador (BA). É possível notar que existem paleoníveis (amostras LOE) no intervalo temporal das oscilações de alta frequência.

Sobre as oscilações de alta frequência, Angulo et al. (2006) destacam algumas datações analisadas por Martin et al. (2003) derivadas de conchas contidas em beach-rocks e camadas sedimentares, bem como de restos de madeira. Eles ressaltam que estes indicadores sofrem retrabalhamento antes da deposição e que as respectivas datações indicariam idades mais antigas para a formação do depósito sedimentar.

Ao inserir as idades no envelope de comportamento do nível relativo do mar proposto por Angulo et al. (2006), é possível notar que parte das idades obtidas por LOE possuem altimetria mais elevada que a curva máxima proposta como tendência regional ao norte da latitude de $28^{\circ} \mathrm{S}$. Isso provavelmente pode ser explicado pela diferença de tipo de indicadores utilizados para construção da curva. Nesse caso, os autores utilizaram preferencialmente os vermitídios, considerado um indicador do tipo biológico, cujo o análogo moderno sugere uma margem de precisão de $\pm 0,1$ $\mathrm{a} \pm 1,0 \mathrm{~m}$ para o caso da costa brasileira. Já os análogos das cristas de praia na área de estudo, sugerem uma margem de precisão de $\pm 2,5 \mathrm{a} \pm 3,2 \mathrm{~m}$, considerando a espessura do pacote praial (figura 5B). Outro elemento que também pode ter contribuído para a altimetria mais elevada das idades das cristas de praia é a presença de cobertura eólica, conforme apontado anteriormente, principalmente para o caso das amostras do flanco sul. Apesar dessas questões, as amostras obtidas por LOE também acompanham a tendência de diminuição do nível relativo do mar nos últimos 4.000 anos AP, assim como observado na curva de Martin et al. $(1997,2003)$.

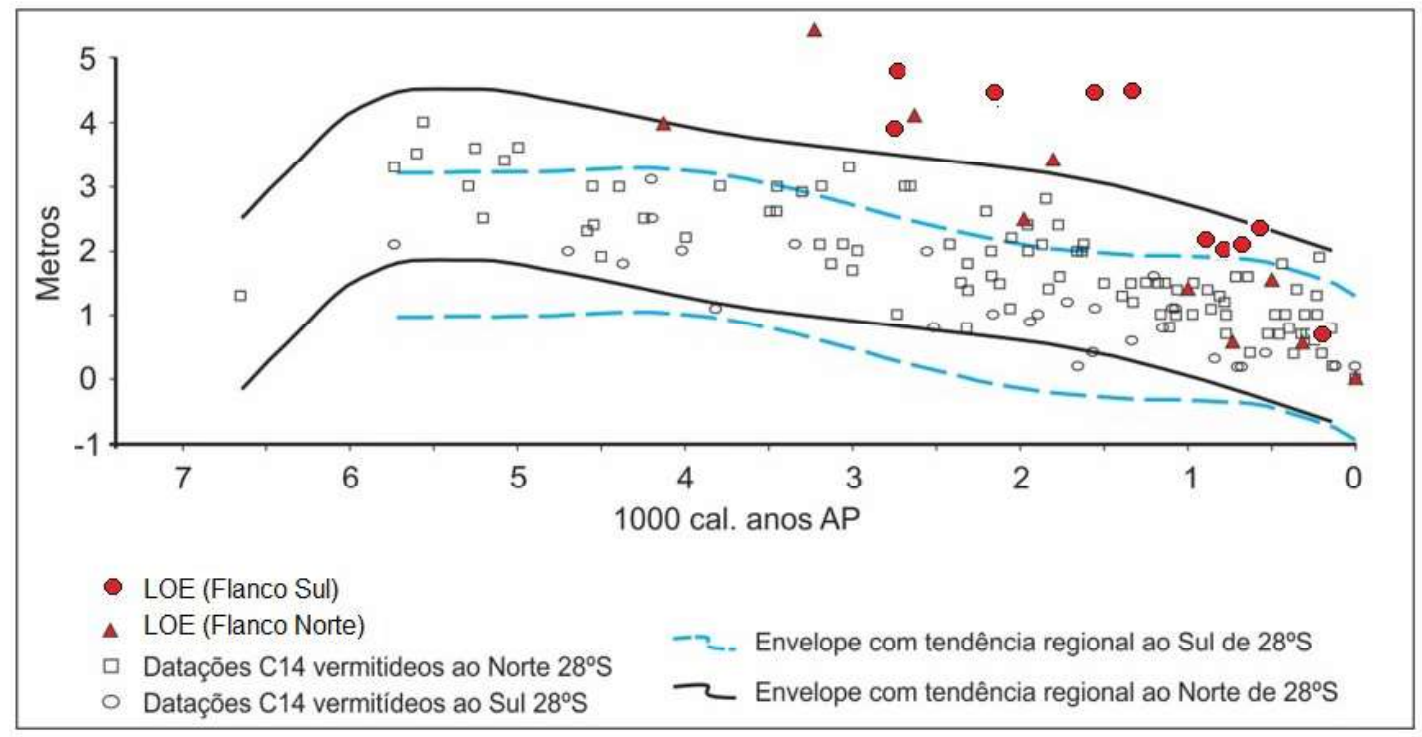

Figura 8 - Localização espaço-temporal das amostras de LOE no envelope de curvas construidas por Angulo et al. (2006). Notar que parte dos paleoniveis encontram-se acima dos indicadores estabelecidos por datações em vermitídeos. Essas diferenças podem estar relacionadas às distintas margens de precisão referentes ao indicador biológico e ao indicador do tipo geomorfológico, como as cristas de praia. 


\section{Conclusões}

As idades obtidas por LOE indicam diferenças entre os flancos da planície costeira do delta do rio Paraíba do Sul, no que se refere ao processo de construção de ambas. No flanco norte, a idade N3 (4.130 \pm 580 anos) marca o início da progradação da planície, como resposta ao aporte sedimentar do rio Paraíba do Sul e a diminuição do nível relativo do mar após o Máximo Transgressivo do Holoceno, posterior há 5.500 anos AP (Martin et al. 2003; Angulo et al. (2006). A associação entre a topografia e as idades mostram, inclusive, uma componente de regressão forçada referente a esse processo de progradação.

No flanco sul, a datação nas cristas próximas aos truncamentos erosivos sugere que os ciclos erosivos ou de interrupção da progradação podem ultrapassar um século. Esses processos podem explicar a não preservação de cristas de idades semelhantes ao do flanco norte no início da planície, visto que a amostra mais interiorizada foi datada em $2.860 \pm 390$ anos.

As estimativas das taxas de progradação mostram que as taxas foram mais rápidas no flanco sul do que o flanco norte, apresentando cerca de 5,0 e 3,0 m/ano, respectivamente. Esse resultado sugere a possibilidade de uma segunda fonte sedimentar, além do rio Paraíba do Sul, para a construção da planície no flanco sul. Além disso, nos últimos mil anos, as taxas de progradação foram aceleradas em ambos os flancos.

Para a utilização das cristas de praia enquanto paleoindicador geomorfológico de comportamento do nível do mar, a comparação com a análogo moderno mostrou-se fundamental para a correlação com as curvas estabelecidas por Martin et al. $(1997,2003)$ e Angulo et al. (2006). Em função dos mecanismos de gênese distintos entres as cristas de praia referentes ao flanco norte e ao flanco sul, bem como a ocorrência de cobertura eólica neste último, a margem de precisão variou entre $\pm 2,5$ a $\pm 3,2 \mathrm{~m}$. Especificamente no caso da curva de Martin et al. (1997, 2003), as idades estabelecidas por LOE parecem não corroborar as oscilações de alta frequência estabelecidas pelos autores.

O estabelecimento de idades a partir da LOE no delta do rio Paraíba do Sul corroboraram muitas discussões anteriormente debatidas por Martin et al. (1993), a partir de idades estabelecidas por Radiocarbano. Porém, os novos resultados de idades numéricas estabelecidas diretamente nas cristas de praia levantaram novas discussões e questionamentos acerca da evolução do delta. Especificamente as idades N1 e N2, mostram que o Pleistoceno Superior e a transição entre o Pleistoceno/Holoceno precisam ser melhor investigados, de preferência associando métodos de subsuperfície como o Radar de Penetração do Solo e sondagens.

\section{Referências Bibliográficas}

ANGULO, R. J.; Lessa, G. The Brazilian sea level curves: a critical review with emphasis on the curves from Paranaguá and Cananéia regions. Marine Geology, n.140, p.141-166. 1997.

ANGUlO, R. J.; LESSA, G. C.; SOUZA, M. C. A critical review of mid- to late-Holocene sea-level fluctuations on the eastern Brazilian coastline. Quaternary Science Reviews, n.25, p.486-506. 2006.

ANGULO, R. J.; SOUZA, M. C. Revisão conceitual de indicadores costeiros de paleoníveis marinhos quaternários no Brasil. Quaternary and Environmental Geosciences, 05(2):01-32. 2004.

ARGYILAN E. P.; FORMAN S. L.; JOHNSTON J. W; WILCOX D.A. Optically stimulated luminescence dating of late Holocene raised strandplain sequences adjacent to Lakes Michigan and Superior, Upper Peninsula, Michigan, USA. Quaternary Research, 63:122- 135. 2005.

ASHTON, A. D. e GIOSAN, L. Wave-angle control of delta evolution. Geophysical Research Letters 38, p. 1-6, 2011.

ASHTON, A. e MURRAY, A. B. Delta simulations using a one-line model coupled with overwash. Proceedings of Coastal Dynamics. ASCE. 2005.

AZEVEDO, M. V. H. Atafona, Patrimônio Mar Adentro: Formação, Planejamento e Destruição do Balneário de Atafona - RJ. 2004. 107 p. Dissertação (Mestrado em Planejamento Regional e Gestão de Cidades), Universidade Cândido Mendes.

BANERJEE D.; HILDEBRAND A. N.; MURRAY-WALLACE C. V.; BOURMAN R. P.; BROOKE B. P.; BLAIR M. New quartz SAR-OSL ages from the stranded beach dune sequence in south-east South Australia. Quaternary Science Reviews, 22:1019-1025. 2003.

BASTOS, A. C. Análise morfodinâmica e caracterização dos processos erosivos ao longo do litoral norte fluminense, entre Cabiúnas e Atafona. 1997. 133 p. Dissertação (Mestrado em Geologia e Geofísica Marinha), Instituto de Geociências, Universidade Federal Fluminense, Niterói 
BITENCOURT, V. J. B.; DILLENBURG, S. R.; BARBOZA, E. G.; MANZOLLI, R. P.; CARON, F.; SAWAKUCHI, A. O. Datação por Luminescência Opticamente Estimulada (LOE) de uma planície de cordões litorâneos do litoral norte do Rio Grande do Sul, Brasil. Quaternary and Environmental Geosciences, 08(2):01-08. 2017.

BHATTACHARYA, J. P.; GIOSAN, L. Wave-influenced deltas: geomorphological implications for facies reconstruction. Sedimentology, 50, p.187-210, 2003.

BOTHA, G. A.; PORAT, N.; HALDORSEN, S.; DULLER, G. A. T.; TAYLOR, R.; ROBERTS, H. M. Beach ridge sets reflect the late Holocene evolution of the St Lucia estuarine lake system, South Africa. Geomorphology, 318, p.112-127. 2018.

BRISTOW C. S.; PUCILLO K. Rates of coastal progradation from sediment volume using GPR and OSL: the Holocene fill off Guichen Bay, Quantifying South-east South Australia. Sedimentology, 53:769-788. 2006.

CASSAR, J. C. M.; NEVES, C. F. Aplicação das rosas de transporte litorâneo à costa norte fluminense. Revista Brasileira de Engenharia, Caderno de Recursos Hídricos. Associação Brasileira de Recursos Hídricos - ABRH, São Paulo, SP, v. 11, p. 81-106, 1993.

CLARKE M. L., RENDELL H. M., WINTLE A. G. Quality assurance in luminescence dating. Geomorphology, 29:173185. 1999.

COHEN, M. C. L.; FRANÇA, M. C.; ROSSETTI, D. F.; PESSENDA, L.C.R.; GIANNINI, P. C. F.; LORENTE, F. L.; BUSO JR. A. A.; CASTRO, D.; MACARIO, K. Landscape evolution during the late Quaternary at the Doce River mouth, Espírito Santo State, Southeastern Brazil. Palaeogeogr. Palaeoclimatol. Palaeoecol. 415, 48-58. 2014.

DA LUZ, C. F. P.; BARTH, O. M.; SILVA, C. G. Dinâmica temporal na lagoa do Campelo, região norte do estado do Rio de Janeiro, baseada em estudos palinológicos. Revista Brasileira de Paleontologia, 9(1):127-136, Janeiro/Abril 2006.

DIAS, G. T. M. O complexo deltáico do Rio Paraíba do Sul. In: IV Simpósio do Quaternário. Brasil. Publicação Especial n.2 (CTCQ/SBG). p 58-88, 1981.

DIAS G. T. M.; KJERFVE B. Barrier and Beach Ridge Systems of Rio de Janeiro Coast. In: S. Dillenburg; P. Hesp (eds.). Geology and Geomorphology of Holocene Coastal Barriers of Brazil. Berlin Heidelberg: Springer Verlag, v.107, p. 225248. 2009.

DILlENBURG, S. R.; BARBOZA, E. G.; ROSA, M. L. C.
C.; CARON, F.; CANCELLI, R.; SANTOS-FISCHER, C. B.; LOPES, R. P.; RITTER, M. N. Sedimentary records of Marine Isotopic Stage 3 (MIS 3) in southern Brazil. Geo-Marine Letters. Springer-Verlag GmbH Germany, part of Springer Nature, 2019. https://doi.org/10.1007/s00367-019-00574-2.

DOMINGUEZ, J. M. L.; MARTIN, L.; BITTENCOURT, A. C. S. P. Esquema evolutivo da sedimentação Quaternária nas feições deltaicas dos rios São Francisco (SE/AL), Jequitinhonha (BA), doce (ES) e Paraíba do Sul (RJ). Revista Brasileira de Geociências, 11(4), p. 227-237, 1981.

FORSYTH, A. J.; NOTT, J.; BATEMAN, M. D.; BEAMAN, R. J. Juxtaposed beach ridges and foredunes within a ridge plain Wonga Beach, northeast Australia. Marine Geology, 307-310; p.111-116. 2012.

GUEDES, C. C. F.; GIANNINI, P. C . F.; SAWAKUCHI, A. O.; DEWITT, R.; NASCIMENTO JR, D.R. ; AGUIAR, V. A. P.; ROSSI, M. G. Determination of controls on Holocene barrier progradation through application of OSL dating: The Ilha Comprida Barrier example, Southeastern Brazil. Marine Geology, n.285, p. 1-16. 2011.

HESP P. A.; DILLENBURG S. R.; BARBOZA E. G.; TOMAZELLI L. J.; AYUP-ZOUAIN R.N.; ESTEVES L. S.; GRUBER N. S.; TOLDO-JR. E.; TABAJARA, L. L. C; CLEROT, L.C.P. Beach ridges, foredunes or transgressive dunefields? Definitions and an examination of the Torres to Tramandaí barrier system, Southern Brazil. Anais da Academia Brasileira de Ciências, 77 (3): 493-508. 2005.

LAMBECK, K.; CHAPPELL, J. Sea level change through the last glacial cycle. Science 292:679-686. 2001.

MACHADO, K. M. Dinâmica Sedimentar na Planície do Paraíba do Sul-RJ. 2009. Dissertação (Mestrado em Geologia e Geofísica Marinha). Instituto de Geociências, Universidade Federal Fluminense, Niterói (RJ).

MARTIN, L.; SUGUIO, K.; FLEXOR, J. M. As flutuações de nível do mar durante o quaternário superior e a evolução geológica de "deltas” brasileiros. Boletim IG-USP. Publicação Especial, n.15. 1993. https://doi.org/10.11606/issn.2317-8078. v0i15p01-186

MARTIN, L.; DOMINGUEZ, J. M. L.; BITTENCOURT, A. C. S. P. Fluctuating Holocene sea levels is eastern and southeastern Brazil: evidence from a multiple fossil and geometric indicators. Journal of Coastal Research, n.19, p.101-124. 2003.

MARTIN, L.; BITTENCOURT, A. C. S. P.; DOMINGUEZ, J. M. L.; FLEXOR, J. M.; SUGUIO, K. Oscillations or not oscillations, that is the question: Comment on ANGULO, R. J.; 
LESSA, G. C. The Brazilian sea-level curves: a critical review with emphasis on the curves from the Paranagua and Cananeia regions. Marine Geology, 50(1-4), 179-187. 1998.

MELLO, G. S.; MACHADO, B. A.; ROCHA, T. B. AVALIAÇÃO DOS IMPACTOS DA EROSÃO COSTEIRANO DISTRITO DE ATAFONA(RJ), ENTRE OS ANOS DE 2005 E 2016. In: Anais do $12^{\circ}$ Sinageo - Simpósio Nacional de Geomorfologia. 2018.

MURRAY A. S.; WINTLE A.G. Luminescence dating of quartz using an improved single- aliquot regenerative-dose protocol. Radiation Measurements, 32:57-73. 2000.

MURRAY-WALLACE C. V.; BANERJEE D.; BOURMAN R. P.; OLLEY J. M.; BROOKED B.P. Optically stimulated luminescence dating of Holocene relict foredunes, Guichen Bay, South Australia. Quaternary Science Reviews, 21:1077-1086. 2002.

NASCIMENTO, F. J. S.; BARBOZA, E. G.; FERNANDEZ, G. B.; ROCHA, T. B.; MINELI, T. D.; ESTEVES, T. Análise cronoestratigráfica dos cordões litorâneos na planície costeira da foz do rio Itabapoana (Espírito Santo, Brasil). Rev. Bras. Geomorfol. (Online), São Paulo, v.19, n.3 (Jul-Set) p.503-523, 2018.

NIELSEN, A.; MURRAY, A. S.; PEJRUP, M.; ELBERLING, B. Optically stimulated luminescence dating of a Holocene beach ridge plain in Northern Jutland, Denmark. Quaternary Geochronology, 1:305-312. 2006.

OTVOS E.G. Beach ridges - definitions and significance. Geomorphology, 32: 83-108. 2000.

RABINEAU, M.; BERNÉ, S.; OLIVET J. L.; ASLANIAN, D.; GUILLOCHEAU, F.; JOSEPH, P. Paleo sea levels reconsidered from direct observation of paleoshoreline position during Glacial Maxima (for the last 500,000 yr). Earth and Planetary Science Letters, 252 (2006) 119-137.

RANASINGHE, R. Assessing climate change impacts on open sandy coasts: A review. Earth-Science Reviews. 160 (2016) 320-332.

REIMANN, T.; NAUMANN, M.; TSUKAMOTO, S.; FRECHEN, M. Luminescence dating of coastal sediments from the Baltic Sea coastal barrier-spit Darss-Zingst, NE Germany. Geomorphology, 122:264-273. 2010.

RICHARDSON, C. A. Residual luminescence signals in modern coastal sediments. Quaternary Science Reviews, 20:887 892. 2001.

RINK, G. I.; LÓPEZ, W. J. SL-based lateral progradation and aeolian sediment accumulation rates for the Apalachicola
Barrier Island Complex, North Gulf of Mexico, Florida. Geomorphology, 123:330-342. 2010.

ROCHA T. B; FERNANDEZ, G. B.; PEIXOTO, M. N. O; RODRIGUEZ, A. Arquitetura deposicional e datação absoluta das cristas de praia pleistocênicas no complexo deltaico do Paraíba do Sul (RJ). Brazilian Journal of Geology, 43(4): 711-724. 2013.

ROCHA, T. B.; FERNANDEZ, G. B.; RODRIGUES, A. Registros de erosão e progradação revelados por radar de penetração do solo (GPR) na barreira regressiva pleistocênica do complexo deltaico do Rio Paraíba do Sul (RJ). Quaternary and Environmental Geosciences, 08(1):24-37. 2017.

ROCHA, T. B.; MACHADO, B. A.; SILVA, J. C.; MELLO, G. S.; PEREIRA, T. G.; FERNANDEZ, G. B. Interação morfodinâmica entre praia e duna frontal no delta do rio Paraíba do Sul (RJ) a partir de uma década de monitoramento. Rev. Bras. Geomorfol. (Online), São Paulo, v.19, n.2, (Abr-Jun) p.283-301, 2018.

ROSSETTI, D. F.; POLIZEL, S. P.; COHEN, M. C. L.; PESSENDA, L. C. R. Late Pleistocene-Holocene evolution of the Doce River delta, southeastern Brazil: Implications for the understanding of wave-influenced deltas. Marine Geology, 367 (2015) 171-190.

SALLUN, A.E.M.; SUGUIO, K.; TATUMI, S.H.; MARCIO YEE, M.; SANTOS, J.; BARRETO, A.M.F. Datação absoluta de depósitos quaternários brasileiros por luminescência. Revista Brasileira de Geociências, 37(2), p.402-413. 2007.

SALVATERRA, A. S; SANTOS, R. F.; SALAROLI. A. B.; FIGUEIRA, R. C. L; MAHIQUES, M. M. Evidence of a Marine Isotope Stage 3 transgression at the Baixada Santista, southeastern Brazilian coast. Brazilian Journal of Geology, 47: 693 702. 2017. https://doi.org/10.1590/2317-4889201720170057.

SANTOS, R. A. Processos de Erosão e Progradação entre as praias de Atafona e Grussaí - RJ. 2006. 36 p. Monografia (Graduação em Geografia) - Universidade Federal Fluminense - UFF. Niterói, RJ.

SCHEFFERS, A.; ENGEL, M.; SCHEFFERS, S.; SQUIRE, P.; KELLETAT, D. Beach ridge systems - archives for Holocene coastal events? Progress in Physical Geography, 36(1) 5-37. 2012.

SHACKLETON, N. J. The 100,000-year Ice-Age cycle found to lag temperature, carbon dioxide, and orbital eccentricity. Science, 289 (2000) 1897-1902.

SILVA C.G. Estudo da evolução geológica e geomorfológica 
da região da Lagoa Feia, RJ. 1987. Dissertação de mestrado, Departamento de Geologia, Universidade Federal do Rio de Janeiro, 116 p.

SILVA, A. L. C.; SILVA, M. A. M.; GAMBÔA, L. A. P.; RODRIGUES, A. R. Sedimentary architecture and depositional evolution of the Quaternary coastal plain of Maricá, Rio de Janeiro, Brazil. Brazilian Journal of Geology, 44(2):191-206. 2014.

SOUZA, C.R.G.; SOUZA, FILHO P.W.M.; ESTEVES, L.S.; VITAL, H.; DILLEMBURG, S.R.; PATCHINEELEM, S.M.; ADDAD, J.E. Praias arenosas e erosão costeira. In: SOUZA, C.R.G.; SUGUIO, K.; OLIVEIRA, A.M.S; OLIVEIRA, P.E. Quaternário do Brasil. Editora Holos, Ribeirão Preto. Capítulo 7, p.130-152. 2005.

SOUZA, T. A.; BULHÕES, E.; AMORIM, I. B. S. Ondas de tempestade na costa Norte Fluminense. Quaternary and Environmental Geosciences (2015) 06(2):10-17.

SOUZA, R. D. Propagação de ondas para águas rasas no litoral norte fluminense. 2011. 156 p. Dissertação (Mestrado em Geofísica e Geologia Marinha) Universidade Federal Fluminense - UFF. Niterói, RJ

SUGUIO K.; MARTIN L. Brazilian Quaternary Formations
- The states of São Paulo and Bahia litoral zone evolutive schemes. Anais da Academia Brasileira de Ciências, v.48, p.325-334. 1976.

SUGUIO, K.; MARTIN, L.; BITTENCOURT, A. C. S.P.; DOMINGUEZ, J. M. L.; FLEXOR, J. M.; AZEVEDO, A. E. G. Flutuações do nível relativo do mar durante o quaternário superior ao longo do litoral brasileiro e suas implicações na sedimentação costeira. Revista Brasileira de Geociências, n.15, p.273-286. 1985.

TAMURA T. Beach ridges and prograded beach deposits as palaeoenvironment records. Earth-Science Reviews, 114: 279-297. 2012.

TAMURA, T.; ITO, K.; INOUE, T.; SAKAI, T. Luminescence dating of holocene beach-ridge sands on the Yumigahama Peninsula, Western Japan. Geochronometria 44 (2017): 331-340.

VASCONCELOS, S. C.; ROCHA, T. B.; PEREIRA, T. G.; ALVES, R. A.; FERNANDEZ, G. B. Gênese e morfodinâmica das barreiras arenosas no flanco norte do delta do rio Paraíba do Sul (RJ). Revista Brasileira Geomorfologia, v.17, n.3, p. 481-498, 2016. 